\title{
REFERENCES
}

1. Richard Arens, Extension of functions on fully normal spaces, Pacific J. Math. 2 (1952), 11-22.

2. O. Hanner, Retraction and extension of mappings of metric and non-metric spaces, Ark. Mat. 2 (1952), 315-360.

3. F. Hausdorff, Erweiterung einer stetigen Abbildung, Fund. Math. 30 (1938), 40-47.

4. C. W. Saalfrank, A generalization of the concept of absolute retract, Proc. Amer. Math. Soc. 12 (1961), 374-378.

University of Alabama

\section{A COVERING THEOREM FOR CONVEX MAPPINGS ${ }^{1}$}

THOMAS H. MACGREGOR

The following theorems are classical. Proofs can be found in [1, pp. 214, 223].

THEOREM 1. If $f(z)$ is regular and univalent in $|z|<1, f(0)=0$ and $f^{\prime}(0)=1$ then the image domain covers the circle $|w|<1 / 4$.

THEOREM 2. If $f(z)$ is regular and univalent in $|z|<1, f(0)=0$, $f^{\prime}(0)=1$ and the image $D$ is convex, then $D$ covers the circle $|w|<1 / 2$.

The purpose of this note is to show that Theorem 2 can be proven as a simple consequence of Theorem 1 . Suppose then that $f(z)$ satisfies the hypotheses of Theorem 2 and $f(z) \neq c$. Let $g(z)=(f(z)-c)^{2}$. Suppose that $z_{1}$ and $z_{2}$ are distinct points in the unit circle and $g\left(z_{1}\right)=g\left(z_{2}\right)$. Then either $f\left(z_{1}\right)=f\left(z_{2}\right)$ or $2^{-1}\left(f\left(z_{1}\right)+f\left(z_{2}\right)\right)=c$. The first equation cannot hold since $f(z)$ is univalent in $|z|<1$. Neither can the second equation hold, for $D$ is convex and therefore the average of every two points in $D$ is also in $D$. This proves that $g(z)$ is univalent in $|z|<1$. The function $h(z)=\left(c^{2}-g(z)\right) / 2 c$ satisfies the hypotheses of Theorem 1 , and $h(z) \neq c / 2$ since $f(z) \neq c$. Therefore, $|c / 2| \geqq 1 / 4$, $|c| \geqq 1 / 2$.

\section{REFERENCE}

1. Z. Nehari, Conformal mapping, New York, McGraw-Hill, 1952.

\section{LAFayette College}

Received by the editors January 22, 1963.

1 This paper was written during the term of the National Science Foundation grant NSF-GP-161. In content this paper is a segment of the author's dissertation. 